\title{
Fear of the Pandemic of the New Variant of Covid - 19 in the Population of the Puente Piedra District in North Lima
}

Section: Healthcare

ISI Impact Factor (2020-21): 1.899

IC Value (2020): 91.47 $\operatorname{SJIF}(2020)=7.893$

\section{Rosa PS ${ }^{1}$, Hernan MS ${ }^{2}$, Eduardo MS ${ }^{2}$, Anika RA}

(ब) (1) (8)

Copyright@IJCRR

'Research Directorate, Universidad María Auxiliadora, 15314, Lima-Perú; ${ }^{2}$ Researcher, Research Directorate, Universidad María Auxiliadora, 15314, Lima-Perú.

\section{ABSTRACT}

Background: Fear is one of the perceptions that respond to how vulnerable a person is to a situation of risk of contagion by COVID-19 and compromises their well-being

Objective: The objective is to determine the fear of pandemic due to the new variant of COVID - 19 in the population of the Puente Piedra district in North Lima. It is a quantitative, non-experimental, descriptive, cross-sectional study, with a total population of 577 participants, who answered a virtual survey with sociodemographic data and the COVID-19 fear scale.

Results: In its results, we observe that in the population of the district of Puente Piedra, $82(14.2 \%)$ presents a low effect on fear of COVID - 19, 260 (45.1\%) a moderate effect on fear of COVID - 19 and 235 (40.7\%) a high effect on fear of COVID - 19.

Conclusions: It is concluded that the negative emotional charge due to the fear of COVID - 19 considerably affects the mental health of the population.

Key Words: Fear, Coronavirus, Covid - 19, Pandemic, Effect of fear

\section{INTRODUCTION}

Worldwide, when the first outbreak of the coronavirus (COVID - 19) was reported, there was concern and fear due to the alarming number of infections generated by COVID - 19, and that consequently affected almost all countries, mainly developing countries. ${ }^{1}$

Fear is one of the predictors of an adaptation response to a risk situation, although it is true, the COVID-19 pandemic, ${ }^{2}$ has generated a high index of fear due to excessive infections, deaths and chaos in the population, ${ }^{3}$ this affects people's mental health because the real threat from COVID - 19 can generate consequences that harm mental health.,

Although, the fear to be infected is also increasingly susceptible in people ${ }^{6}$ since the relationship of contagion and fear increases every day due to the fact that people have unstable mental health, where the mental load they have does not apt to be able to adapt to the new reality due to the pandemic. ${ }^{7}$

Likewise, not only is it enough to present fear to know that the population has unstable health, ${ }^{8}$ factors such as anxie- ty, stress, depression, mood swings and sadness have been seen, ${ }^{9}$ they are generators of mental instability in times pandemic due to COVID - $19,{ }^{10}$ and due to the new variants of COVID - 19 worldwide, has generated instability at a social and personal level in the population, ${ }^{11}$ since the fear is even more serious than what was seen last year, ${ }^{12}$ because now the numbers of infections are higher and they occur in younger people today. ${ }^{13,14}$

COVID-19 has currently generated a negative impact on the population's coping behaviors to cope with the pandemic, ${ }^{15}$ and therefore, the population cannot recover psychologically from it, generating even more mental problems. ${ }^{16}$ For this reason, the consequences generated by COVID - 19 in people's mental health will become more noticeable in the long term when people can go back to their activities. ${ }^{17}$

In the study carried out in Israel, ${ }^{18}$ with the participation of 649 people, they interpreted in their research that gender was significantly associated with fear of COVID - 19 and the female sex was the one that presented higher rates of fear than the male sex, represented in the factors of emo-

\section{Corresponding Author:}

Perez-Siguas Rosa, Researcher, Research Directorate, Universidad María Auxiliadora, 15314, Lima-Perú. Ph: +51 996826968, Email: rosa.perez@uma.edu.pe

ISSN: 2231-2196 (Print)

Received: 11.04 .2021
ISSN: 0975-5241 (Online)

Revised: 06.04 .2021
Accepted: 21.07 .2021
Published: 01.03 .2022 
tional fear and symptomatic expressions of fear of COVID $-19$.

In a study carried out in Japan, ${ }^{19} 6750$ participants in the study from the adolescent stage to the elderly stage, they observed that in relation to the factors of emotional fear and symptomatic expressions of fear of COVID-19, where the level fear was higher in women and older adults, and the population of women, children, adolescents, the elderly and the poor with pre-existing psychological morbidity, tend to be more vulnerable at a psychological level due to COVID-19.

In a study carried out in Spain, ${ }^{20}$ in 606 university participants in the study, they interpreted that university students had fear of COVID - 19 but it was not highly high, because the isolation and quarantine measure has been effective in university students, because being at home with the family generates greater security and protection that reduces fear.

Therefore, the objective of this research work is to determine the fear of the pandemic due to the new variant of COVID-19 in the population of the Puente Piedra district in North Lima.

Therefore, its research hypothesis is that COVID-19 considerably affects the mental health of the population, generating fear in themselves.

\section{METHODOLOGY}

\section{Type of Research}

In the present reseach, due to its properties and the way of collecting data according to the present variables, it is a quantitative approach, with a descriptive, non-experimental and cross-sectional methodological design. ${ }^{21}$

\section{Population}

The population is made up of 577 participants in total belonging to the Puente Piedra district.

\section{Inclusion criteria}

- Participants residing in the Puente Piedra district.

- Participants ranging from the age of 18 onwards.

- Participants who voluntarily agree to participate in the study and signed the consent informedACTA $\mathrm{N}^{\circ} 049$ 2020-CE/UMA UNIVERSIDAD MARIA AUXILIADORA.

\section{Technique and instrument}

A virtual survey was carried out in the Google form, in which the data instrument Fear of COVID - 19 Scale (FCV - 19S) was written

For the data collection, it has been structured in 2 blocks: 1. Sociodemographic data such as age, sex, marital status, level of education, occupation; 2. FCV - 19S that comprises
7 items in which it presents a one-dimensional dimension, in which it is valued with a Likert-type scale with 5 response options: " $1=$ Totally disagree", " $2=$ Disagree", " $3=$ neither agree nor disagree ", 4 = agree "and" $5=$ Totally agree ", obtaining a total score by adding all the items, so the score would range from 7 to 35 points, where " 7 to 16 " is a low effect of fear of COVID - 19," 17 to 26 "is a moderate effect of fear of COVID - 19" and "27 to 35" is a high effect of fear of COVID - 19, the higher the score the higher it will be the effect of fear about COVID-19 in the population of the Puente Piedra district in North Lima. ${ }^{22,23}$

The validity of the instrument to measure fear of COVID-19 was determined based on the exploratory factor analysis technique. The Kaiser-Mayer-Olkin sample adequacy measure obtained a coefficient of $0.825(\mathrm{KMO}>0.5)$, while the Bartlett sphericity test obtained significant results $\left(\mathrm{X}^{2}\right.$ approx. $=4128.250 ; \mathrm{gl}=21 ; \mathrm{p}=0.000$ ).

The reliability of the instrument was determined based on Cronbach's Alpha statistical test, for all the items $(i=7)$, resulting in a coefficient of $0.923(\alpha>0.8)$.

\section{Place and application of the instrument}

The survey was carried out virtually through the Google form which will measure the fear of the pandemic due to the new variant of COVID - 19 in the population of the Puente Piedra district in North Lima.

First, it coordinated with the heads of family of each household to be able to carry out the questionnaires in order to obtain data for the research, in addition to providing them with the corresponding details about the study.

After conducting the virtual surveys, the support of the study population gave us considerable benefit and satisfaction at the time of making the database since they collaborated in the study.

\section{RESULTS}

Below is a summary table of the surveys carried out following the guidelines corresponding to the research work:

In Figure 1, it observes that in the population of the Puente Piedra district, $82(14.2 \%)$ present a low effect on fear of COVID - 19, $260(45.1 \%)$ a moderate effect on fear of COVID - 19 and 235 (40.7\%) a high effect on fear of COVID - 19.

In Figure 2, it can see that the fear of COVID - 19 in the population of Puente Piedra district, the female sex presents a higher effect on fear of COVID - 19, where 149 $(53 \%)$ have a high effect on fear of COVID - 19 than males $86(29.1 \%)$ and males have a moderate effect on fear of COVID - 19, where 159 (53.7\%) have a moderate effect of fear of COVID - 19 than those of female gender 101 
(35.9\%), and a low effect on fear of COVID - 1951 (17.2) of the male sex and $31(11 \%)$ of the female sex.

Table 1 shows the fear of the pandemic due to the new variant of COVID-19 and the civil status of the population of the Puente Piedra district, in which it was determined with the Pearson chi-square test $\left(\mathrm{X}^{2}\right)$. The level of significance of the test obtained a value of $0.14(\mathrm{p}>0.05)\left(\mathrm{X}^{2}=30.398\right.$; d. $\mathrm{f}=$ 8 ). Therefore, a hypothesis of association between both variables is not rejected.

Therefore, we can interpret that in the single population present a low effect on fear of COVID - 1943 (52.4\%), while the cohabiting population has a moderate effect of fear of COVID - 19177 (68.1\%) and the cohabiting population has a high effect on fear of COVID - 19142 (60.4\%).

Table 2 shows the fear of the pandemic due to the new variant of COVID-19 and the occupation of the population of the Puente Piedra district, in which it was determined with the Pearson chi-square test $\left(\mathrm{X}^{2}\right)$. The level of significance of the test obtained a value of $1.99(\mathrm{p}>0.05)\left(\mathrm{X}^{2}=115.540\right.$; d.f $=6$ ). Therefore, a hypothesis of association between both variables is not rejected. Therefore, we can interpret that the population with eventual occupation presents a low effect of fear of COVID - 1952 (63.4\%) and also present a moderate effect of fear of COVID - 19149 (57.3\%), and the population with stable occupations have a high effect on fear of COVID - 19121 (51.5).

\section{DISCUSSION}

The study has been carried out from a prevention perspective towards mental health in the population, in which it seeks to develop strategies that allow the population to face dangerous situations that compromise their mental health, and allow them to cope with this situation in the news about the pandemic of the new variant of COVID -19 in our country.

In the results regarding the fear of COVID - 19, it is observed that the population of the Puente Piendra district has a high effect on fear of COVID - 19, this is due to the fact that the new variant of COVID - 19 has generated a shock in the country, where the feeling of fear has been seen considerably, and highly affects people's mental health, due to factors such as the increase in positive cases of COVID-19 due to the new variant, the alarming level of contagion in the population and in addition to the fact that the number of deaths is increasing every time. They argue that the mental burden that people have due to the new variant of COVID-19 is increasingly alarming, factors such as fear, worry, despair and anguish, predispose people even more to an impact negative that not only compromises their mental health, but also their ability to adapt to the COVID-19 pandemic. ${ }^{15}$
In the results in relation to sex, we observe that the female sex is the one that presents a higher effect on fear of COVID-19 than the male sex, this is interpreted that the female sex is very susceptible to presenting feelings of fear generated by the pandemic, although it is also generated because one of the members of their family is infected by COVID-19, and because of this, they have to find a way to get a bed in some hospital where the high demand for cases makes it impossible to get a bed for treatment, in addition to the supply of oxygen, due to the long queues that are made to obtain an oxygen balloon to keep it stable while it continues its treatment, all this makes mental health is seriously compromised. They argue that the psycho-emotional level is highly compromised in the female sex and due to this, it presents factors such as anguish, hopelessness, sadness, worry and these are causing them to generate fear at an emotional level in themselves making its recovery difficult in its mental wellbeing. ${ }^{18}$ They argue that the female sex is the most vulnerable at the mental level, because it is not able to cope with the consequences generated by COVID-19 and therefore, the feeling of fear is made every time more noticeable because it cannot cope adequately. ${ }^{19}$

This problem that is seen in the country by the new variant of COVID - 19 has been hard both in our health system and in the population, therefore, more infections are seen in health professionals, and many of them due to COVID - 19 have died, because the implementation of prevention for the care of COVID - 19 patients is increasingly scarce.

Therefore, in its hypothesis, we can confirm that the results in the study in relation to the fear of COVID-19 considerably affect mental health that depended on sex, where the female sex was the one that was most compromised.

\section{CONCLUSIONS}

It is concluded that the negative emotional burden due to the fear of COVID-19 considerably affects the mental health of the population, so strategies are sought to maintain or improve people's mental health through cellphone or virtual care provided by health professionals.

It is concluded to make health strategies that allow maintaining or improving the adaptation capacity of people to cope with the COVID-19 pandemic.

It is concluded that sex, marital status, type of quarantine and the history of positive relatives for COVID - 19 are the main determinants of fear that is related to COVID - 19.

This study will be beneficial for future studies since it details important data about the data collection instrument that details important points about the fear of COVID - 19, in which it will allow more studies to be carried out in our country. 


\section{Conflict of Interest}

The authors declare no conflict of interest.

Funding Source

This research work doesn't have Funding Sources

\section{ACKNOWLEDGMENT}

Authors acknowledge the immense help received from the scholars whose articles are cited and included in references of this manuscript. The authors are also grateful to authors / editors / publishers of all those articles, journals, and books from where the literature for this article has been reviewed and discussed.

\section{Author's Contributions}

Rosa PS: Conceived and designed the analysis, wrote the paper and translation.

Hernan MS: Collected the data, Performed the analysis.

Eduardo MS: Contact with the people for the survey taking.

Anika RA: Contributed data and analysis tools.

\section{REFERENCES}

1. Tsang S, Avery A, Duncan G. Fear and depression linked to COVID-19 exposure A study of adult twins during the COVID-19 pandemic. Psychiatry Res. 2021;296:113699.

2. Mertens G, Gerritsen L, Duijndam S, Salemink E, Engelhard I. Fear of the coronavirus (COVID-19): Predictors in an online study conducted in March 2020. J Anxiety Disord. 2020;74:102258.

3. Andrade E, Pereira L, Oliveira A, Orlando D, Alves D, Guilarducci J, et al. Perceived fear of COVID-19 infection according to sex, age and occupational risk using the Brazilian version of the Fear of COVID-19 Scale. Death Stud. 2020;0(0):1-10.

4. Pradhan M, Chettri A, Maheshwari S. Fear of death in the shadow of COVID-19: The mediating role of perceived stress in the relationship between neuroticism and death anxiety. Death Stud. 2020;0(0):1-5.

5. Servidio R, Bartolo M, Palermiti A, Costabile A. Fear of COVID-19, depression, anxiety, and their association with Internet addiction risk in a sample of Italian students. J Affect Disord Reports. 2021;4:100097.

6. Hoong K, Kemp R. Understanding and reducing the fear of COVID-19. J Zhejiang Univ Sci B. 2020;21(9):752-754.
7. Collins F. Measuring COVID-19-related Fear and Threat in Australian, Indian, and Nepali University Students. Pers Individ Dif. 2021; 175:110693.

8. Ramezani N, Ashtari F, Bastami E, Ghaderi K, Hosseini S, Naeini M, et al. Fear and anxiety in patients with multiple sclerosis during COVID-19 pandemic; report of an Iranian population. Mult Scler Relat Disord. 2021;50:102798.

9. Sahu D, Pradhan S, Sahoo D, Patra S, Singh A, Patro B. Fear and anxiety among COVID-19 Screening Clinic Beneficiaries of a tertiary care hospital of Eastern India. Asian J Psychiatr. 2021;57:102543.

10. Tayyib N, Alsolami F. Measuring the extent of stress and fear among Registered Nurses in KSA during the COVID-19 Outbreak. J Taibah Univ Med Sci. 2020;15(5):410-416.

11. Niño M, Harris C, Drawve G, Fitzpatrick K. Race and ethnicity, gender, and age on perceived threats and fear of COVID-19: Evidence from two national data sources. SSM - Popul Heal. 2021;13:100717.

12. Le K, Nguyen M. The psychological burden of the COVID-19 pandemic severity. Econ Hum Biol. 2021;41:100979.

13. Pavlakis S, McAbee G, Roach E. Fear and Understanding in the Time of COVID-19. Pediatr Neurol. 2020;111:37-38.

14. González M, Delgado B, Ortega A, Romero M, Carrillo M. Fear of Covid-19 in Madrid: Will Patients Attend for Dental Care? Int Dent J. 2021;13(1):72-77.

15. Kirby T. New variant of SARS-CoV-2 in UK causes surge of COVID-19. Lancet Respir Med. 2021;9(2):20-1.

16. Asai K, Wakashima K, Toda S, Koiwa K. Fear of novel coronavirus disease (COVID-19) among pregnant and infertile women in Japan. J Affect Disord Reports. 2021;4:100104.

17. Fitzpatrick K, Drawve G, Harris C. Facing new fears during the COVID-19 pandemic: The State of America's mental health. J Anxiety Disord. 2020;75:102291.

18. Tzur D, Grossman A, Bloch Y, Mayer Y, Shiffman N, Mendlovic S. Fear of COVID-19 scale: Psychometric characteristics, reliability and validity in the Israeli population. Psychiatry Res. 2020;289:113100.

19. Midorikawa H, Aiba M, Lebowitz A, Taguchi T, Shiratori Y, Ogawa T, et al. Confirming validity of The Fear of COVID-19 Scale in Japanese with a nationwide large- scale sample. PLoS One. 2021;16(2):246840.

20. Martínez M, Martínez A, Criado J, Armesilla M, Latorre J. The fear of COVID-19 scale: Validation in spanish university students. Psychiatry Res. 2020;293:113350.

21. Fernández C, Baptista P. Metodología de la Investigación. 6ta ed. México: Mc Graw-Hill/Interamericana. 2015. 1-634 .

22. Huarcaya J, Villarreal D, Podestà A, Luna M. Psychometric Properties of a Spanish Version of the Fear of COVID-19 Scale in General Population of Lima, Peru. Int J Ment Health Addict. 2020;1(1):1-14.

23. Pakpour A, Griffiths M. The fear of COVID-19 and its role in preventive behaviors. J Concurr Disord. 2020;2:58-63. 


\section{Fear of COVID - 19}

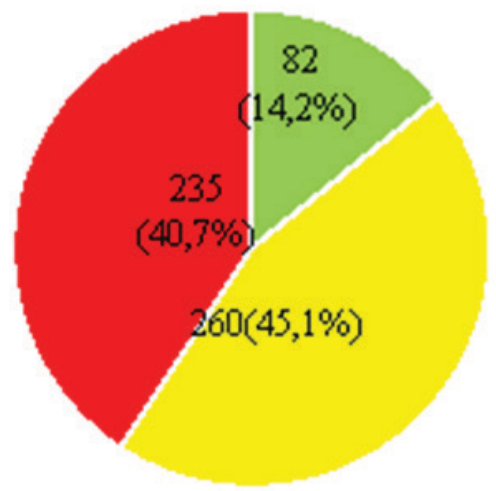

" Low effect on fear of COVID - 19

- Moderate effect on fear of COVID - 19

- High effect on fear of COVID - 19

Figure 1: Fear of the pandemic due to the new variant of COVID - 19 in the population of the Puente Piedra district in North Lima.
Fear of COVID-19 in relation to sex

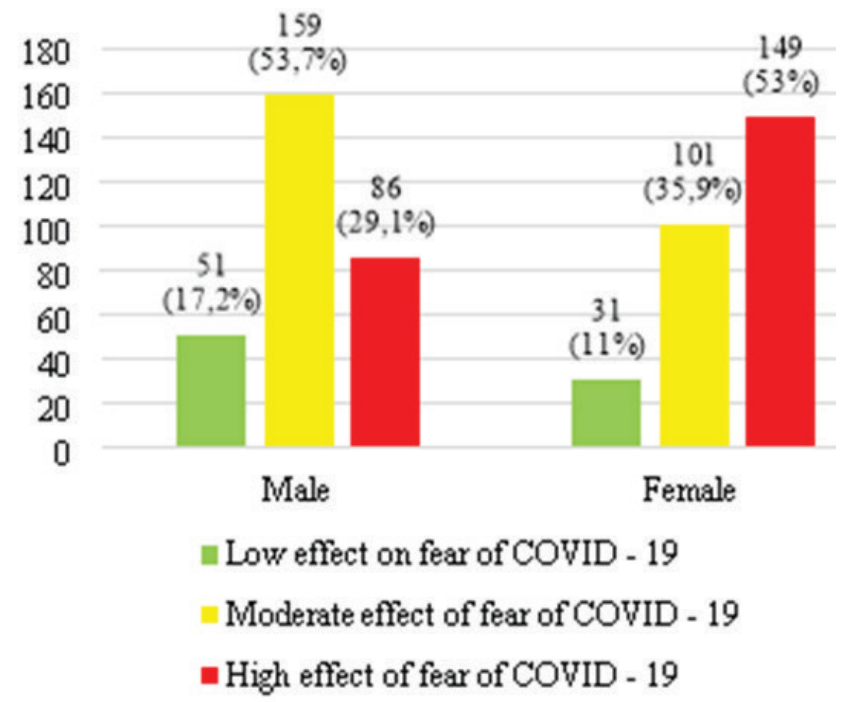

Figure 2: Fear of the pandemic due to the new variant of COVID - 19 in relation to sex in the population of the Puente Piedra district in North Lima.

Table I: Fear of the pandemic due to the new variant of COVID - 19 in relation to civil status in the population of the Puente Piedradistrict

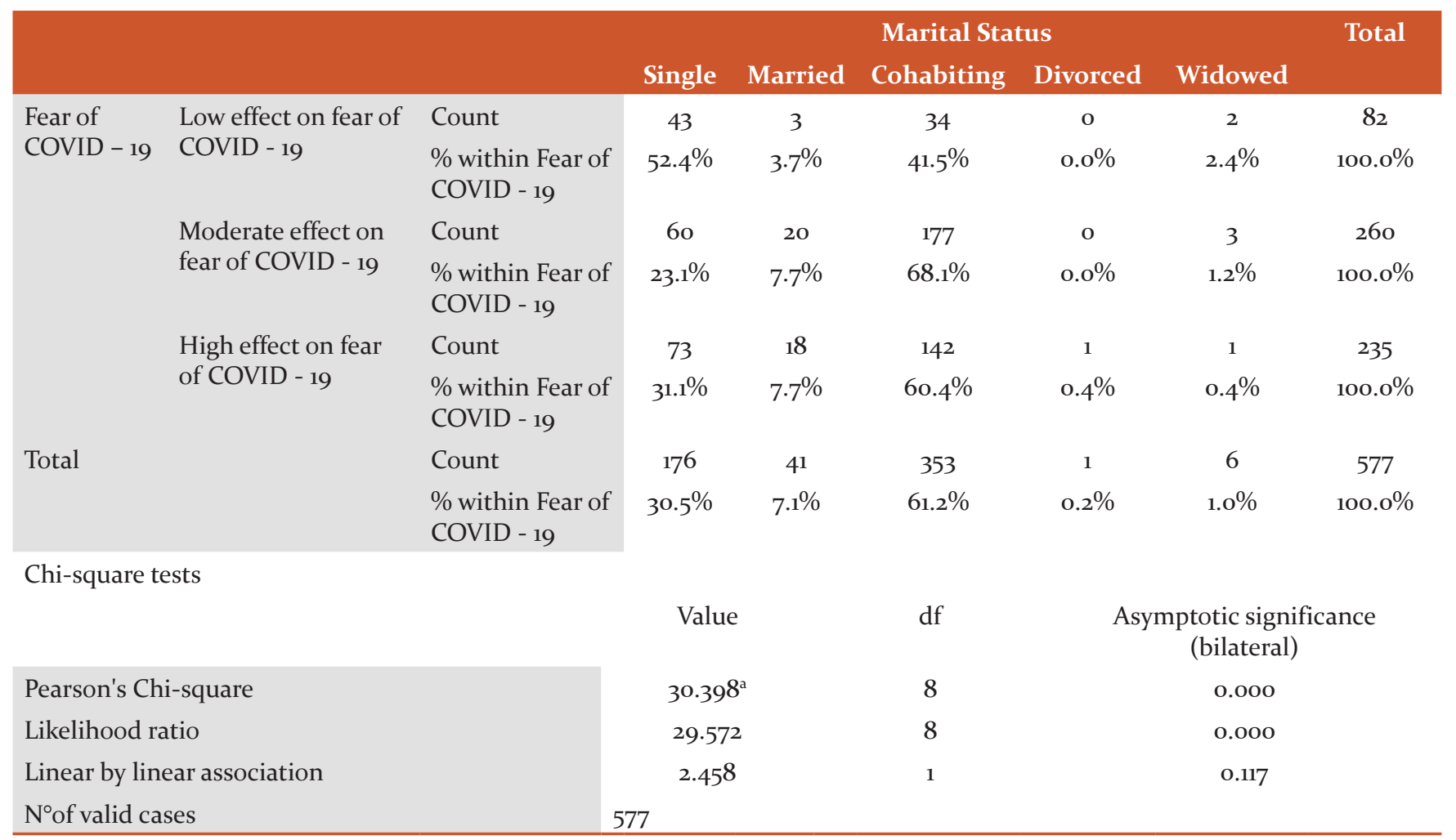

a. 6 cells $(40.0 \%)$ have expected a count less than 5 . The minimum expected count is .14. 
Table 2: Fear of the pandemic due to the new variant of COVID - 19 in relation to civil status in the population of the Puente Piedra district

\begin{tabular}{|c|c|c|c|c|c|c|c|c|}
\hline & & & & & & ccupancy & & Total \\
\hline & & & & Stable & Eventual & No occupation & Student & \\
\hline Fear of COVID - 19 & Low effect on fear of & Count & & 12 & 52 & 17 & 1 & 82 \\
\hline & COVID - 19 & $\begin{array}{l}\text { \% within Fear o } \\
\text { COVID - } 19\end{array}$ & & $14.6 \%$ & $63.4 \%$ & $20.7 \%$ & $1.2 \%$ & $100.0 \%$ \\
\hline & Moderate effect on fear & Count & & 48 & 149 & 50 & 13 & 260 \\
\hline & of COVID - 19 & $\begin{array}{l}\text { \% within Fear o } \\
\text { COVID - } 19\end{array}$ & & $18.5 \%$ & $57 \cdot 3 \%$ & $19.2 \%$ & $5.0 \%$ & $100.0 \%$ \\
\hline & High effect on fear of & Count & & 121 & 49 & 65 & o & 235 \\
\hline & COVID - 19 & $\begin{array}{l}\text { \% within Fear o } \\
\text { COVID - } 19\end{array}$ & & $51.5 \%$ & $20.9 \%$ & $27.7 \%$ & $0.0 \%$ & $100.0 \%$ \\
\hline Total & & Count & & 181 & 250 & 132 & 14 & 577 \\
\hline & & $\begin{array}{l}\% \text { within fear of } \\
\text { COVID - } 19\end{array}$ & & $31.4 \%$ & $43 \cdot 3 \%$ & $22.9 \%$ & $2.4 \%$ & $100.0 \%$ \\
\hline Chi-square tests & & & & & & & & \\
\hline & & & Value & & $\mathrm{df}$ & Asymptot & $\begin{array}{l}\text { ic significan } \\
\text { eral) }\end{array}$ & ce (bilat- \\
\hline Pearson's Chi-squar & & & $115 \cdot 540^{a}$ & & 6 & & .000 & \\
\hline Likelihood ratio & & & $123 \cdot 397$ & & 6 & & .000 & \\
\hline Linear by linear asso & ciation & & 18.334 & & 1 & & .000 & \\
\hline $\mathrm{N}^{\circ}$ of valid cases & & & 577 & & & & & \\
\hline
\end{tabular}

a. 1 cells $(8.3 \%)$ have expected a count less than 5 . The minimum expected count is 1.99 . 